\title{
Ileal Symbiont Intracellularis, an Obligate Intracellular Bacterium of Porcine Intestines Showing a Relationship to Desulfovibrio Species
}

\author{
CONNIE J. GEBHART, ${ }^{1 *}$ SUSAN M. BARNS, ${ }^{2}$ STEVEN MCORIST, ${ }^{3}$ GAO-FENG LIN, ${ }^{1}$ \\ AND GORDON H. K. LAWSON ${ }^{3}$ \\ Department of Veterinary PathoBiology, College of Veterinary Medicine, University of Minnesota, \\ St. Paul, Minnesota 551081' Department of Biology, Indiana University, Bloomington, \\ Indiana $47405^{2}$; and Department of Veterinary Pathology, University of \\ Edinburgh, Edinburgh EH25 9RG, Scotland ${ }^{3}$
}

\begin{abstract}
A new genus and species of obligate intracellular bacteria found in porcine intestines are described. Growth on any bacteriological medium deprived of living cells has not been demonstrated. The organism has been grown intracellularly in cell culture. The 16S rRNA gene sequence data, DNA probe results, and microscopic observations provide evidence that these bacteria differ from those in other described genera and that they belong to the delta subdivision of the class Proteobacteria. We have amplified and sequenced the $16 \mathrm{~S}$ ribosomal DNA of four preparations of the intracellular bacterium from pigs. For this, intracellular organisms were released and purified from the infected cells without culture techniques. After DNA purification, the polymerase chain reaction with primers complementary to highly conserved eubacterial sequences was used to amplify regions of $16 \mathrm{~S}$ ribosomal DNA which were subsequently cloned (in some cases) and sequenced directly by standard techniques. The sequences obtained from each preparation were identical and were most similar to that of a sulfate-reducing proteobacterium, Desulfovibrio desulfuricans ATCC 27774 (91\% similarity). An oligonucleotide probe complementary to a hypervariable region of the $16 \mathrm{~S}$ rRNA sequence of the bacterium hybridized with intracellular organisms obtained from porcine intestines. The bacterium is a gram-negative, curved rod with tapered ends. It multiplies intracellularly in the cytoplasm of ileal epithelial cells by septation. The vernacular name Ileal symbiont (IS) intracellularis is proposed for this bacterium. The type strain of IS intracellularis is strain 1482/89 grown in cell culture from a pig affected by proliferative enteropathy. It is deposited in the National Collection of Type Cultures, Colindale, London, as NCTC 12656.
\end{abstract}

Nearly 20 years ago, an intracellular bacterium within the ileal epithelial cells of pigs with proliferative enteropathies was described (28). These organisms were curved bacilli, located freely within the cytoplasm of epithelial cells, and they were consistently associated with a marked proliferation of immature crypt epithelial cells, particularly in the ilea of pigs $(26,27)$ affected by porcine proliferative enteropathy or enteritis. The consistent morphological and immunological recognition of these intracellular organisms in cases of the disease suggests that they are involved in its etiology (14, $15,27)$.

The disease is infectious and is transmitted by oral exposure of animals to diseased mucosa. Experimentally produced lesions demonstrate proliferative intestinal epithelia with large numbers of intracellular, curved organisms (27). It remains to be shown that the intracellular organisms are the single cause of the proliferation observed in the infected enterocytes. Proliferative enteritis has also been described for other mammals, including hamsters, ferrets, and foxes. In these animals, the intracellular organisms are also observed within the proliferating epithelial cells of the intestine. Immunohistological staining suggests that these organisms are related to the one found in pigs $(15,27)$.

The identity and origin of the intracellular bacteria and their relationship to the pathogenesis of the disease have not been resolved. Several species of organisms with a similar curved shape and size are cultivated from the porcine lesions of proliferative enteropathy, and they include Campylobac-

\footnotetext{
* Corresponding author.
}

ter coli, Campylobacter hyointestinalis, and Campylobacter mucosalis $(7,8)$. So far, however, transmission and immunohistological studies have shown that none of these culturable organisms is the intracellular organism of proliferative enteropathy (27). Also, a monoclonal antibody prepared against the intracellular organism, which had been purified from lesions without culture, reacted with intracellular bacteria in sections of lesions from other pigs but not with any culturable organisms (15). Finally, antigenic comparison of whole-cell and outer membrane preparations of each of the Campylobacter species and the intracellular bacterium showed that the intracellular bacterium was unrelated (14).

DNA probes specific for the intracellular bacteria, purified without culturing, have been generated and characterized previously (6). These probes hybridized with porcine mucosae obtained from pigs that had proliferative enteropathies but not with nondiseased mucosae. These probes failed to hybridize with any of the commonly isolated porcine Campylobacter species. Also, species-specific DNA probes for $C$. mucosalis and $C$. hyointestinalis, the two Campylobacter species commonly isolated from pigs, do not react with the intracellular organism (7). Therefore, the intracellular organism is an as yet unidentified species.

Parameters for the determination of the phylogeny of intracellular bacteria have recently been outlined $(4,23-25)$. These include oligonucleotide probe hybridization and $16 \mathrm{~S}$ rRNA sequence analysis of cultured and uncultured organisms. With specific ribosomal DNA (rDNA)-targeted primers and by polymerase chain reaction, obligate intracellular bacteria have been detected and identified previously $(5,25)$. Specific DNA probes and monoclonal antibodies can iden- 
tify the intracellular organisms of proliferative enteropathy in situ $(6,15)$. These reagents do not react with any organism of similar morphology cultivated from the porcine intestine $(6,14)$. Attempts to culture the intracellular organism on cell-free artificial media have failed. The organism has been cultivated intracellularly in cell culture (13). In this paper, we present genomic and phenotypic evidence that this organism probably constitutes a new genus and species of the class Proteobacteria, for which we propose the vernacular name Ileal symbiont (IS) intracellularis.

\section{MATERIALS AND METHODS}

Organisms and purification procedures. The intracellular bacteria used in this study were purified directly from ileal mucosae of pigs with proliferative enteropathies without culture, as described previously (15). Briefly, affected mucosae were washed in saline, digested with trypsin, homogenized to release intracellular bacteria, and then filtered through 2.5-, 1.0-, and 0.65- $\mu \mathrm{m}$-pore-size filters. Filtrates were further purified by magnetic separation with specific monoclonal antibody (15) according to the manufacturer's instructions (Dynabead, Oslo, Norway). Final suspensions contained $>99 \%$ curved bacteria which resembled the intracellular organism, as assessed by examination of smears stained with specific monoclonal antibodies (15). Normal porcine mucosa containing no detectable intracellular organisms was treated similarly, except that no magnetic separation was applied.

Four cell suspensions, designated 1269/76, 1268/84, 764/ 86 , and $872 / 87$, were prepared. All were derived from pigs with affected mucosae which demonstrated lesions of proliferative enteropathy (27). Affected mucosae which demonstrated high numbers of intracellular organisms but which yielded low numbers of Campylobacter species on culture were used. Two further strains, designated 1482/89 and $916 / 91$, were isolated separately in pure culture in an epithelial cell line, the rat enterocyte line IEC-18, as described elsewhere (13). Each isolate was initially prepared from other pigs with affected mucosae, as described above.

Microscopic observations. For transmission electron microscopy, portions of infected intestines or cells were fixed in $2 \%$ glutaraldehyde in cacodylate buffer and postfixed in osmium tetroxide, and ultrathin sections of embedded specimens were stained with uranyl acetate and lead citrate. Samples of bacterial strains purified from intestines or cells as described above were stained with $4 \%$ sodium phosphotungstate. Grids were examined with a Philips electron microscope (EM400).

For light microscopy, preparations were stained with Gram stain, Ziehl-Neelsen stain for acid fastness (10a), and flagellum and capsule stains.

Phenotypic investigations. Media and conditions for attempts at cultivation on cell-free media included a variety of enrichment media incubated under aerobic, microaerophilic, and anaerobic atmospheres at 25,37 , and $42^{\circ} \mathrm{C}$.

Rat enterocyte cell cultures infected with the two strains $1482 / 89$ and $916 / 91$ were used to investigate some of the phenotypic features of the bacteria. Cycloheximide, glutamate, and ATP were added to cultures to test for bacterial energy pathways (16). Fresh bacterial preparations were inoculated into the chorioallantoic or yolk sac membranes of sterile, 5-day-old chicken embryos and examined for bacterial growth 5 days later (21).

DNA extraction and nucleic acid sequencing. Nucleic acids were purified from $0.1 \mathrm{~g}$ of each bacterial isolate and control tissue by enzymatic digestion and extraction with phenol and chloroform as described previously (6). Nucleic acids were precipitated from solution by the addition of 2 volumes of ethanol.

The polymerase chain reaction was used to amplify eubacterial 16S rRNA genes from each nucleic acid sample with primer pairs fD1-rP1, fD1-rP2, and fD2-rP1, described by Weisburg et al. (30). Each primer pair is capable of initiating amplification of nearly full-length $16 \mathrm{~S}$ rDNA from a taxonomically wide range of bacteria. Reaction products from each primer pair were pooled. Unincorporated nucleotides and primers were removed with Centricon $100 \mathrm{col}-$ umns, according to the manufacturer's instructions (Amicon, Beverly, Mass.) and as described previously (11).

The amplification products were either cloned and sequenced as described previously (30) or sequenced directly (33) by annealing approximately $500 \mathrm{ng}$ of each to oligonucleotide sequencing primers complementary to highly conserved regions of eubacterial $16 \mathrm{~S}$ rDNA and by dideoxynucleotide chain termination sequencing with a Sequenase kit (U.S. Biochemical, Cleveland, Ohio). A clone designated pCLO28 was obtained from a genomic library prepared directly from the intracellular organism without amplification (6). The full-length $16 \mathrm{~S}$ rDNA sequence was obtained from this clone. The sequence data were aligned manually with conserved sequence and secondary structural elements,

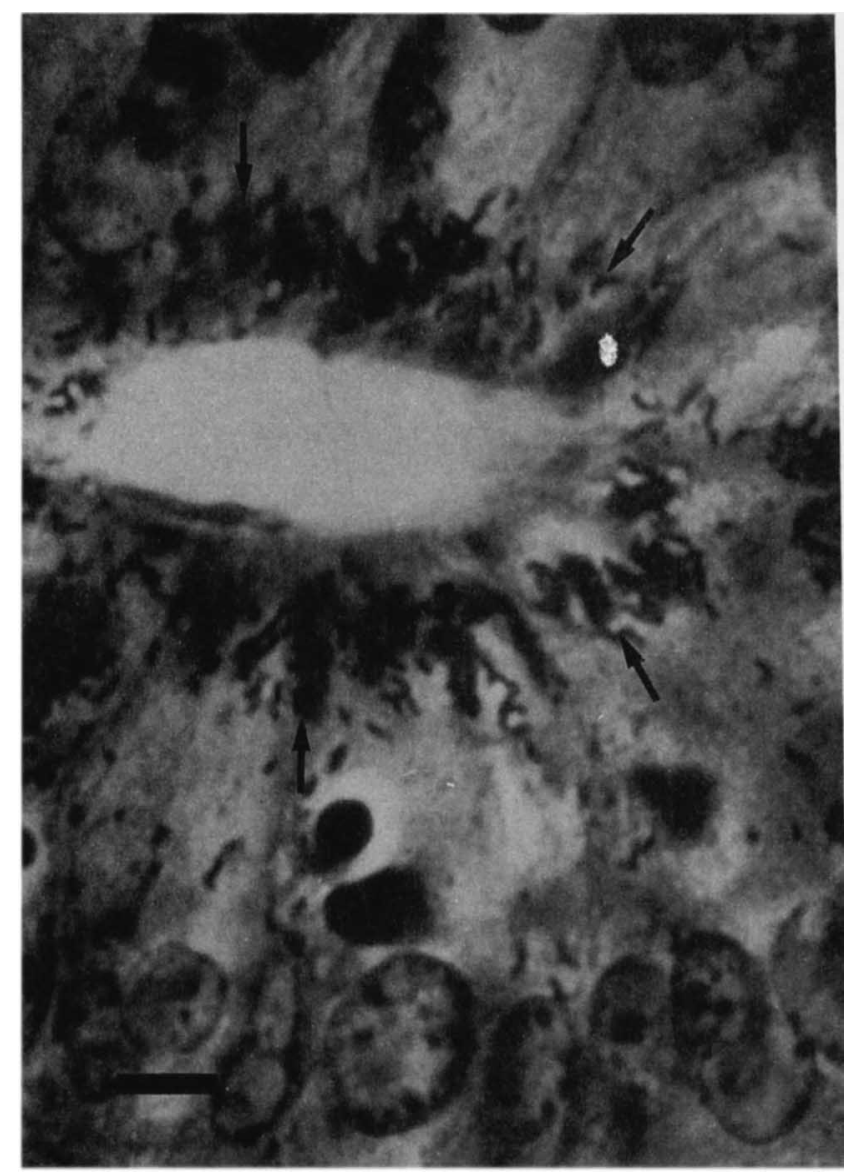

FIG. 1. Warthin-Starry silver-stained section of epithelial cells in the ileum of a pig affected by proliferative enteropathy, showing large numbers of curved, intracellular organisms (indicated by arrows) in the apical cytoplasm. Bar $=5 \mu \mathrm{m}$. 
excluding positions of uncertain homology (10). Pairwise comparisons between homologous nucleotide positions were used to determine sequence similarities by a least-squares distance matrix analysis $(11,17)$.

DNA probe analysis. To confirm the specificity of the sequence we obtained $(4,9)$, a hypervariable region in the $16 \mathrm{~S}$ rDNA sequence unique to the intracellular organism was identified. This region contained nine or more mismatches with analogous sequences of other organisms examined (see Fig. 4). An oligonucleotide probe complementary to the hypervariable region sequence was synthesized and end labelled with digoxigenin (Boehringer Mannheim, Indianapolis, Ind.) as described previously (1). Nucleic acids extracted from diseased and normal pig intestines were immobilized on nylon membranes and hybridized with this probe or an oligonucleotide probe prepared similarly from the homologous region of Campylobacter jejuni as a control.

Nucleotide sequence accession number. The 16S rDNA sequence of strain 1269/76 has been deposited for electronic retrieval from GenBank under accession number L15739 and is available from the authors.

\section{RESULTS AND DISCUSSION}

Microscopic observations. Typical intracellular bacteria within infected porcine epithelial cells are shown in Fig. 1.
All intracellular bacteria were found in the cytoplasm and were not bound to host membrane or within vacuoles. They were generally distributed in the apex of the cell beneath the brush border and did not form masses or inclusion bodies. Thin sections of the intracellular organism (Fig. 1 to 3) showed a gram-negative bacterium with a wavy trilaminar outer envelope, sometimes clearly separated from the cytoplasmic membrane by an electron-lucent zone. The cytoplasm occasionally contained a central area of condensed nucleoplasm representing the nucleoid. Division of bacteria occurred transversely via a central pinching-off process (septation). Bacteria liberated from host cells were gramnegative bacilli, variably curved or sometimes sigmoid, with tapering ends. The cells were 1.25 to $1.75 \mu \mathrm{m}$ long by 0.25 to $0.43 \mu \mathrm{m}$ wide. The surfaces of negatively stained bacteria after release and washing were electron opaque and smooth. Flagella, pili, or fimbriae were not evident. Neither capsules nor spores were observed. The bacteria were gram negative and were acid fast when stained by the modified ZiehlNeelsen method.

Phenotypic investigations. The intracellular bacteria failed to grow on any cell-free medium under aerobic, microaerophilic, or anaerobic conditions at a variety of temperatures (5a). More recently, attempts to cultivate the organism aerobically or anaerobically on sulfate-containing media have also been unsuccessful. We were unable to test the
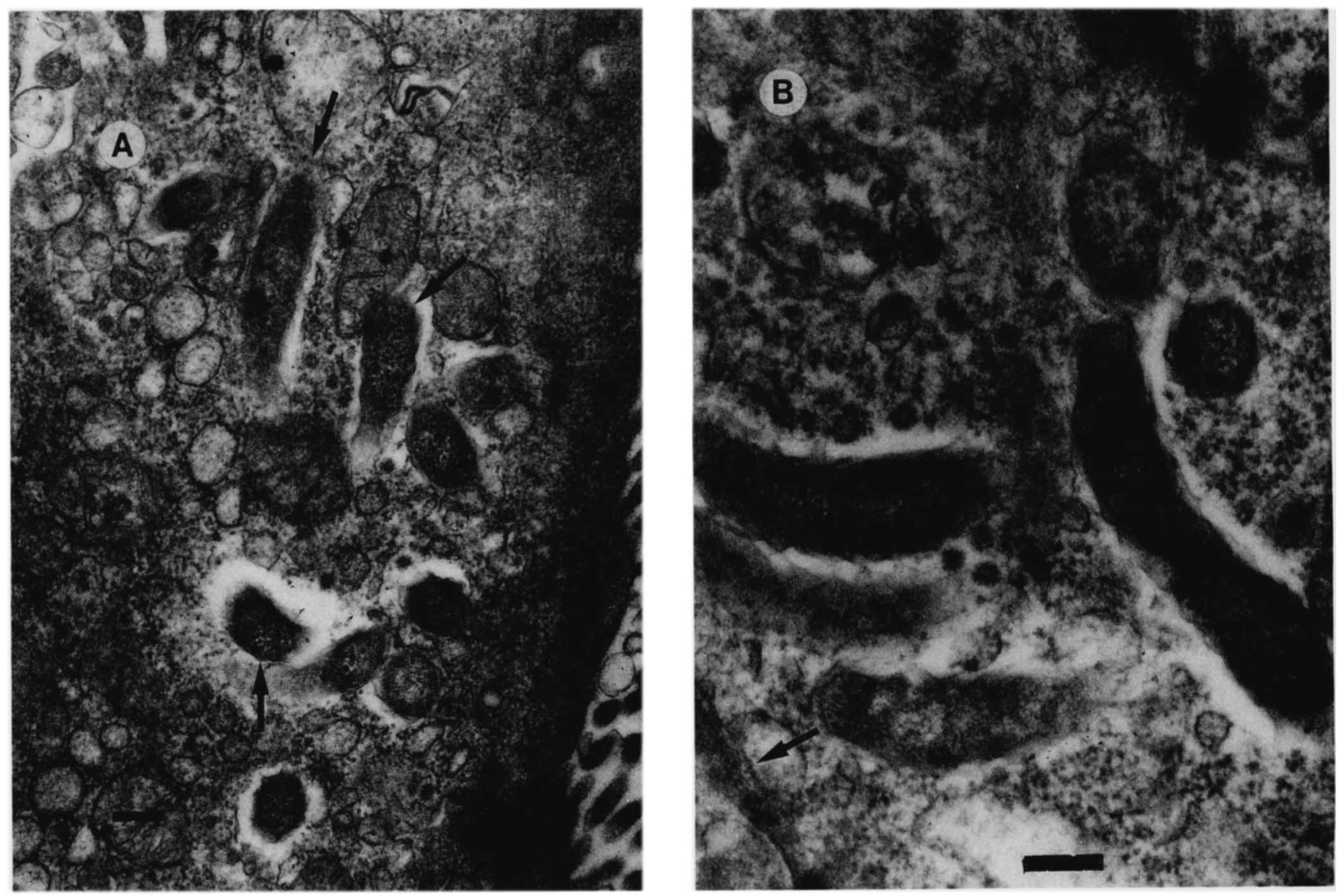

FIG. 2. Electron micrograph of the intracellular organisms in an ultrathin section of the epithelial cell ileum of a pig affected by proliferative enteropathy. (A) Microvilli are observed on the luminal surface of the enterocyte. Arrows point to the organisms. (B) Organisms show the characteristic curved shape and lie free within the cytoplasm. Lateral junction complexes (indicated by arrows) suggest that the bacteria are located near the apical cytoplasm of the cell. Bar (both panels) $=200 \mathrm{~nm}$. 
bacterial preparations for sulfate-reduction properties. Growth of the organism is necessary for this and other phenotypic tests. Also, these bacterial preparations are generally contaminated by low numbers of porcine Campylobacter species, i.e., C. coli, $C$. mucosalis, and $C$. hyointestinalis, which may affect any chemotaxonomic characteristics observed.

The bacteria were cultivated intracellularly in epithelial cell lines, such as the rat enterocyte line IEC-18, in which they were morphologically and immunologically identical to those observed in porcine enterocytes (13). Cycloheximide inhibited intracellular growth. Glutamate or ATP did not stimulate growth. The bacteria did not grow in chicken embryos, despite repeated attempts. These properties differed from those reported previously for other intracellular bacteria (16). Rickettsia and Chlamydia species, while capable of infecting epithelial cells, do not infect mammalian enterocytes (29) and differ from these bacteria in size, life cycle, and morphology. Both Shigella and Rickettsia species enter the cell in a host-derived vacuole but escape the vacuole after entering (16). Shigella species grow on cell-free media.

Genetic relationships. Analysis of complete or partial 16S rDNA sequences from each purified bacterial suspension repeatedly yielded one sequence which was identical to that of clone pCLO28. Sequence comparisons with more than 400 full and partial 16S rRNA sequences available from the Ribosomal RNA Database Project (18) showed highest similarity (91\%) with that of Desulfovibrio desulfuricans (19) but $<80 \%$ similarity with those of any Campylobacter or Helicobacter species $(12,20)$. Further phylogenetic analyses with rRNA sequence data from 26 species of sulfate-reducing eubacteria $(2,3)$ showed greater than $86 \%$ similarity to all sequences of the family Desulfovibrionaceae proposed by Devereux et al. (3), with greatest similarity to that of $D$. desulfuricans ATCC 27774 (91\%). These sequence relationships strongly indicate affiliation of this organism with this coherent group of sulfate-reducing eubacteria. Similarity data from analyses with approximately 1,320 comparable nucleotide positions in the rRNA sequences of $D$. desulfuricans, Myxococcus xanthus, C. jejuni, and Escherichia coli are given in Table 1 . The $16 \mathrm{~S}$ rDNA sequence conformed to the secondary structural models (10) for the delta subdivision of the Proteobacteria.

DNA probe analysis. DNA probe analysis only detected positive hybridization of the intracellular organism-directed oligonucleotide probe with the samples of porcine intestines which had demonstrable intracellular organisms within epithelial cells (data not shown). No hybridization was observed with the $C$. jejuni oligonucleotide probe.

The unique nature of the intracellular organism of porcine proliferative enteropathy was suggested previously by immunological (15) and DNA (6) studies. The present study supports and extends those findings to the level of genetic distinction. Phylogenetic data (31) show that intracellular organisms are often not specifically related to each other and are dispersed among unrelated groups. For example, members of the genus Rickettsia cluster with the alpha subdivision of the class Proteobacteria; Coxiella burnetii is found in the gamma subdivision of the Proteobacteria.

Desulfovibrio species belong to a group of sulfate-reducing bacteria which are morphologically and physiologically diverse $(2,32)$. They utilize either oxidized sulfur compounds or elemental sulfur as electron acceptors. Habitats for these organisms include anaerobic mud, sediments of freshwater and marine environments, and the intestinal tracts of mam-

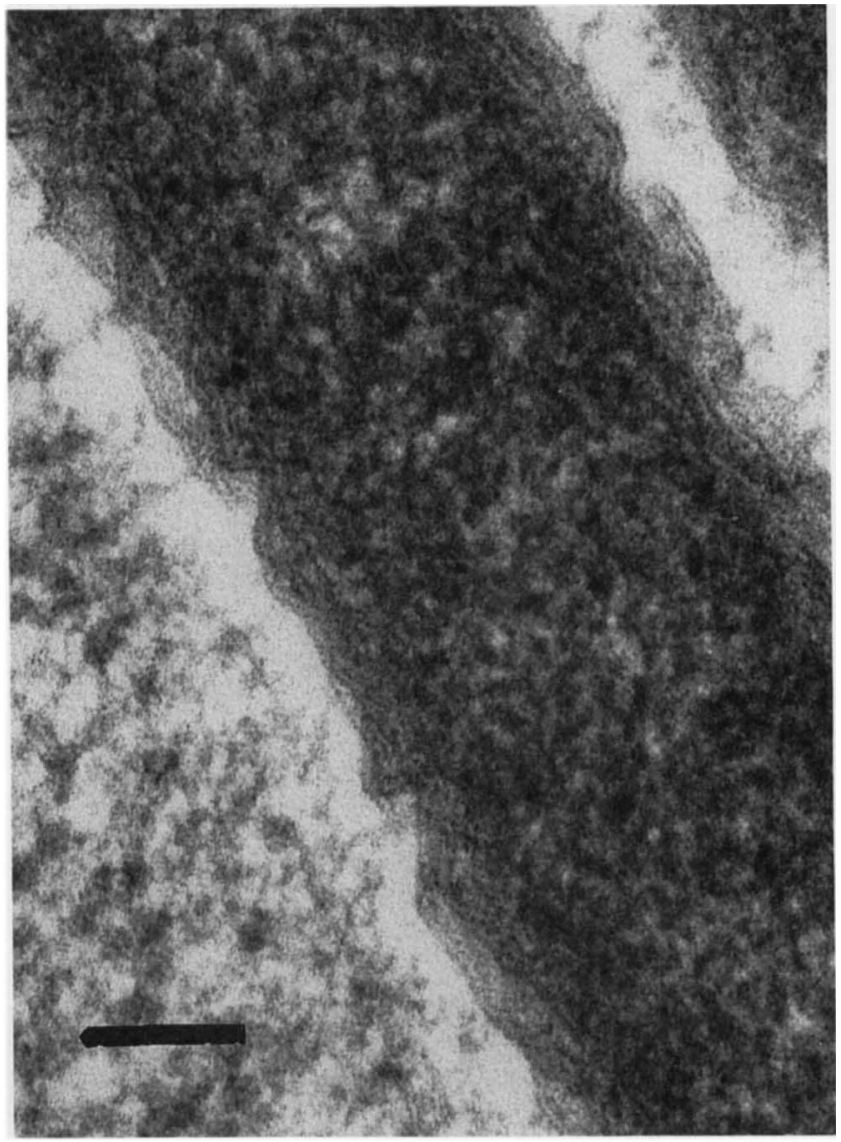

FIG. 3. Electron micrograph of intracellular bacteria illustrating the wavy, trilaminar outer membrane and an obvious nucleoplasm. Bar $=100 \mathrm{~nm}$.

mals (32). Members of the Desulfovibrio genus are rod shaped, helical, vibroid, or spiral. Although the intracellular organism of proliferative enteropathy is morphologically similar to some species in the genus Desulfovibrio, its ability to reduce sulfate is not known. Therefore, it cannot be placed into this genus as it is now described.

Organisms with morphologies, antigenic structures, and habitats similar to those described here have been previously 6identified in hamsters and other mammals $(14,15,27)$. It is therefore possible that other species of this intracellular bacterium may be described in the future. Previous studies have indicated that intracellular bacteria derived from pigs with a variety of clinicopathological forms of proliferative

TABLE 1. 16S rDNA sequence similarity between IS intracellularis and some other eubacterial species

\begin{tabular}{|c|c|c|c|c|c|c|}
\hline \multirow[b]{2}{*}{ Species } & \multirow[b]{2}{*}{$\begin{array}{l}\text { Sub- } \\
\text { group }\end{array}$} & \multicolumn{5}{|c|}{$\%$ Similarity to ${ }^{a}$ : } \\
\hline & & $\begin{array}{c}E . \\
\text { coli }\end{array}$ & $\underset{\text { jejuni }}{C .}$ & $\begin{array}{c}M . \\
\text { xanthus }\end{array}$ & $\begin{array}{c}D . \\
\text { desulfu- } \\
\text { ricans }\end{array}$ & $\begin{array}{c}\text { IS } \\
\text { intracel- } \\
\text { lularis }\end{array}$ \\
\hline E. coli & Gamma & & & & & \\
\hline C. jejuni & Epsilon & 78.5 & & & & \\
\hline M. xanthus & Delta & 81.5 & 78.3 & & & \\
\hline D. desulfuricans & Delta & 81.0 & 79.4 & 82.7 & & \\
\hline IS intracellularis & Delta & 81.8 & 79.0 & 82.5 & 91.0 & \\
\hline
\end{tabular}

\footnotetext{
${ }^{a}$ Regions of uncertain homology were eliminated from the comparison.
} 


\begin{tabular}{|c|c|}
\hline EC & CGUCGUGGACAGAGU-GCCAAGGGC----UUCCGUGUAAGAGUAGAGACUUU \\
\hline $\mathrm{CJ}$ & CGUCGUGGACAGAGA-UUCAAGAUCGUUCGAUCGUGGGAGAAUAGAGAUUUU \\
\hline MX & CGUCGUGGACAGAGA-GUCAAGGGAA--CGCCCGUGAGGGAGUAGAGACUUC \\
\hline DD & CGUCGUGGACAGAGU-GCCGAGGGGC--UUCCCGUGGGGAGGAAAAGCCCUC \\
\hline IO & CGUCGUGGACAGAAC-UCCGAGGGGC--UUUCCGUGGAGAAUUAGAGAAUUC \\
\hline \multirow[t]{2}{*}{ Probe } & 5' CGTCTTG-AGGCTCCCCG--AAAGGCACCTCTTAATC \\
\hline & 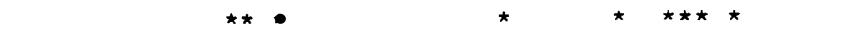 \\
\hline
\end{tabular}

FIG. 4. Sequences of 16S rRNA fragments from position 1008 to position 1055 (relative to $E$. coli base positions). EC, E. coli; CJ, C. jejuni; MX, $M$. xanthus; DD, D. desulfuricans; IO, intracellular organism or IS intracellularis; Probe, oligonucleotide probe sequence used for hybridization. Dashes represent alignment gaps. Asterisks indicate mismatches between the rDNA nucleotide sequence of the intracellular organism and that of $D$. desulfuricans in the target region of the oligonucleotide probe.

enteropathy have similar antigenic structures, particularly a major membrane antigen with a molecular weight of 25,000 (14), and hybridize to specific DNA probes (6).

The 16S rDNA sequence data coupled with the unique curved bacillary shape, habitat, and growth characteristics of this organism will eventually warrant its classification as a new genus and new species. Designation of a family is not yet clear. On the basis of similarity to rDNA sequences from Desulfovibrio species, the organism may have some characteristics of the sulfate-reducing bacteria $(19,22,32)$ and deserve assignment to that genus, although we did not specifically establish these. We propose the establishment of the vernacular name IS intracellularis (in.tra.cell.u.lar.is. L. gen. m., within cells) because of its presence within enterocytes. This should serve as the equivalent to a species name until the level of relationship to Desulfovibrio species can be decided or the organism is further characterized as a new genus within the Proteobacteria.

Description of the ileal symbionts resembling IS intracellularis. The cells are non-spore-forming, curved bacilli (ca. 1.5 by $0.35 \mu \mathrm{m}$ ). Gram negative, retain carbolfuchsin when stained by modified Ziehl-Neelsen method. Nonflagellated. Sections show the cell wall profile of a gram-negative bacterium and the protoplasmic structure of a procaryote. Replicate freely (not membrane enclosed) within the cytoplasm of epithelial cells of the ilea of pigs. Not host membrane bound or within vacuoles. Lie within the apical cytoplasm and do not form masses or inclusion bodies in the cells. Multiply by binary fission (septation). Not cultivable in cell-free media. Grow intracellularly in enterocyte cell cultures. Growth in these cell lines not potentiated by glutamate or ATP. On the basis of the 16S rDNA sequence, these bacteria form a distinct lineage within the delta subdivision of the Proteobacteria. May cause proliferative enteropathy. Morphologically and immunohistologically similar organisms are present within the intestinal epithelial cells of hamsters, foxes, ferrets, and other animals in which they are associated with proliferative enteropathy. We believe that generic status will be justifiable with further data.

The essential description of the porcine ileal symbiont IS intracellularis at this stage of understanding. The cells are non-spore-forming, curved bacilli (ca. 1.5 by $0.35 \mu \mathrm{m}$ ). Gram-negative, retain carbolfuchsin when stained by modified Ziehl-Neelsen method. Nonflagellated. Sections show the cell wall profile of a gram-negative bacterium and the protoplasmic structure of a procaryote. Characteristically replicate freely within the cytoplasm of epithelial cells of the ilea of pigs. Best demonstrated in histological sections by silver-staining techniques. Intracellular organisms can be demonstrated in smears of mucosal tissue with the modified Ziehl-Neelsen acid-fast stain. Multiply by septum formation. Not cultivable in cell-free media. Grow intracellularly in rat enterocyte cells. Identification can be confirmed by use of a monoclonal antibody (15) and a DNA probe (6) specific for this organism. On the basis of the sequence of 16S rDNA, these bacteria are members of the delta subdivision of the Proteobacteria. Isolated from the intestinal epithelial cells of pigs with proliferative enteropathies. The type strain is NCTC $12656(1482 / 89)$.

Designation of the type strain. The type strain for comparative purposes is $1482 / 89$, derived from a suspension of bacteria from a pig affected by proliferative enteropathy in Scotland and maintained in a rat enterocyte cell culture. It is deposited in the National Collection of Type Cultures, Colindale, London, as NCTC 12656.

\section{ACKNOWLEDGMENTS}

We thank Norman R. Pace (Indiana University, Bloomington, Ind.) and David J. Lane and William G. Weisburg (GENE-TRAK Systems, Framingham, Mass.) for supplying essential reagents and valuable advice throughout this research project. We also thank David A. Stahl and Richard Devereux for aligned sequence data used in this analysis.

This work was supported by U.S. Department of Agriculture research grant USDA-89-34116-4877, by a grant from the National Pork Producers Council (C.J.G.), and by the Wellcome Trust of the United Kingdom (S.M.). This material is based, in part, upon work supported under a National Science Foundation Graduate Research Fellowship to S.M.B.

\section{REFERENCES}

1. Amann, R. I., L. Krumholz, and D. A. Stahl. 1990. Fluorescentoligonucleotide probing of whole cells for determinative, phylogenetic, and environmental studies in microbiology. J. Bacteriol. 172:762-770.

2. Devereux, R., M. Delany, F. Widdel, and D. A. Stahl. 1989. Natural relationships among sulfate-reducing eubacteria. J. Bacteriol. 171:6689-6695.

3. Devereux, R., S.-H. He, C. L. Doyle, S. Orkland, D. A. Stahl, J. LeGall, and W. B. Whitman. 1990. Diversity and origin of Desulfovibrio species: phylogenetic definition of a family. J. Bacteriol. 172:3609-3619.

4. Distel, D. L., E. F. DeLong, and J. B. Waterbury. 1991. Phylogenetic characterization and in situ localization of the bacterial symbiont of shipworms (Teredinidae: Bivalvia) by using 16S rRNA sequence analysis and oligodeoxynucleotide probe hybridization. Appl. Environ. Microbiol. 57:2376-2382.

5. Fryer, J. L., C. N. Lannan, S. J. Giovannoni, and N. D. Wood. 
1992. Piscirickettsia salmonis gen. nov., sp. nov., the causative agent of an epizootic disease in salmonid fishes. Int. J. Syst. Bacteriol. 42:120-126.

5a.Gebhart, C. J. Unpublished data.

6. Gebhart, C. J., G.-F. Lin, S. McOrist, G. H. K. Lawson, and M. P. Murtaugh. 1991. Cloned DNA probes specific for the intracellular Campylobacter-like organism of porcine proliferative enteritis. J. Clin. Microbiol. 29:1011-1015.

7. Gebhart, C. J., G.-F. Lin, G. E. Ward, and M. P. Murtaugh. 1990. Species-specific DNA probes for Campylobacter species isolated from pigs with proliferative enteritis. Vet. Microbiol. 24:367-379.

8. Gebhart, C. J., G. E. Ward, and M. P. Murtaugh. 1989. Species-specific cloned DNA probes for the identification of Campylobacter hyointestinalis. J. Clin. Microbiol. 27:27172723.

9. Giovannoni, S., E. F. DeLong, G. J. Olsen, and N. R. Pace. 1988. Phylogenetic group-specific oligodeoxynucleotide probes for identification of single microbial cells. J. Bacteriol. 170:720-726.

10. Gutell, R. R., B. Weiser, C. R. Woese, and H. F. Noller. 1985. Comparative anatomy of $16 \mathrm{~S}$-like ribosomal RNA. Prog. Nucleic Acid Res. Mol. Biol. 32:155-216.

10a.Hendrickson, D. A. 1985. Reagents and stains, p. 1107. In E. H. Lennette, A. Balows, W. J. Hausler, Jr., and H. J. Shadomy (ed.), Manual of clinical microbiology, 4th ed. American Society for Microbiology, Washington, D.C.

11. Lane, D. J. 1991. 16S/23S rRNA sequencing, p. 115-175. In E. Stackebrandt and M. Goodfellow (ed.), Nucleic acid techniques in bacterial systematics. John Wiley \& Sons Ltd., New York.

12. Lau, P. P., B. DeBrunner-Vossbrinck, B. Dunn, K. Miotto, M. T. MacDonnell, D. M. Rollins, C. J. Pillidge, R. B. Hespell, R. R. Colwell, M. L. Sogin, and G. E. Fox. 1987. Phylogenetic diversity and position of the genus Campylobacter. Syst. Appl. Microbiol. 9:231-238.

13. Lawson, G. H. K., S. McOrist, S. Jasni, and R. A. Mackie. 1993. The intracellular bacteria of porcine proliferative enteropathy: cultivation and maintenance in vitro. J. Clin. Microbiol. 31: $1136-1142$.

14. McOrist, S., R. Boid, and G. H. K. Lawson. 1989. Antigenic analysis of Campylobacter species and an intracellular Campylobacter-like organism associated with porcine proliferative enteropathies. Infect. Immun. 57:957-962.

15. McOrist, S., R. Boid, G. H. K. Lawson, and I. McConnell. 1987. Monoclonal antibodies to intracellular Campylobacter-like organisms of the porcine proliferative enteropathies. Vet. Rec. 121:421-422.

16. Moulder, J. W. 1985. Comparative biology of intracellular parasitism. Microbiol. Rev. 49:298-337.

17. Olsen, G. J. 1988. Phylogenetic analysis using ribosomal RNA. Methods Enzymol. 164:793-812.

18. Olsen, G. J., N. Larsen, and C. R. Woese. 1991. The ribosomal
RNA database project. Nucleic Acids Res. 19:2017-2021.

19. Oyaizu, H., and C. R. Woese. 1985. Phylogenetic relationships among the sulfate-respiring bacteria, myxobacteria and purple bacteria. Syst. Appl. Microbiol. 6:257-263.

20. Paster, B. J., and F. E. Dewhirst. 1988. Phylogeny of campylobacters, wolinellas, Bacteriodes gracilis, and Bacteriodes ureolyticus by $16 \mathrm{~S}$ ribosomal ribonucleic acid sequencing. Int. J. Syst. Bacteriol. 38:56-62.

21. Paul, J. 1975. Cell and tissue culture. Churchill Livingstone, Ltd., Edinburgh.

22. Postgate, J. R. 1979. The sulfate-reducing bacteria. Cambridge University Press, Cambridge.

23. Putz, J., F. Meinert, U. Wyss, R. Ehlers, and E. Stackebrandt. 1990. Development and application of oligodeoxynucleotide probes for molecular identification of Xenorhabdus species. Appl. Environ. Microbiol. 56:181-186.

24. Relman, D. A., J. S. Loutit, T. M. Schmidt, S. Falkow, and L. S. Tomkins. 1990. The agent of bacillary angiomatosis: an approach to the identification of uncultured pathogens. N. Engl. J. Med. 323:1573-1580.

25. Relman, D. A., T. M. Schmidt, R. P. MacDermott, and S. Falkow. 1992. Identification of the uncultured bacillus of Whipple's disease. N. Engl. J. Med. 327:293-301.

26. Rowland, A. C., and G. H. K. Lawson. 1974. Intestinal adenomatosis in the pig: immunofluorescent and electron microscopic studies. Res. Vet. Sci. 17:323-330.

27. Rowland, A. C., and G. H. K. Lawson. 1992. Porcine proliferative enteropathies, p. 560-569. In A. D. Leman, B. E. Straw, W. L. Mengeling, S. D'Allaire, and D. J. Taylor (ed.), Diseases of swine, 7 th ed. Iowa State University Press, Ames.

28. Rowland, A. C., G. H. K. Lawson, and A. Maxwell. 1973. Intestinal adenomatosis in the pig: occurrence of a bacterium in affected cells. Nature (London) 243:417.

29. Stanier, R. Y., J. L. Ingraham, M. L. Wheelis, and P. R. Painter. 1986. The microbial world, 5th ed. Prentice-Hall, Inc., Englewood Cliffs, N.J.

30. Weisburg, W. G., S. M. Barns, D. A. Pelletier, and D. J. Lane. 1991. 16S ribosomal DNA amplification for phylogenetic study. J. Bacteriol. 173:697-703.

31. Weisburg, W. G., M. E. Dobson, J. E. Samuel, G. A. Dasch, L. P. Mallavia, O. Baca, L. Mandelco, J. E. Sechrest, E. Weiss, and C. R. Woese. 1989. Phylogenetic diversity of the rickettsiae. J. Bacteriol. 171:4202-4206.

32. Widdel, F. 1986. Sulfate-reducing bacteria and their ecological niches, p. 157-176. In E. M. Barnes and G. C. Mead (ed.), Anaerobic bacteria in habitats other than man. Blackwell Scientific Publishing, London.

33. Zhang, H., R. Scholl, J. Browse, and S. Somerville. 1988. Double stranded DNA sequencing as a choice for DNA sequencing. Nucleic Acids Res. 16:173. 